\title{
A New Basic Chromosome Number for Amaranthus (Amaranthaceae)
}

\author{
M. Pal, D. Ohri and G. V. Subrahmanyam \\ National Botanical Research Institute, Lucknow-226 001, U.P., India \\ Accepted September 1, 1999
}

\begin{abstract}
Summary The chromosome number of Amaranthus tenuifolius Willd. has been found to be $2 \mathrm{n}=28$ which gives a new basic number $(\mathrm{x}=14)$ for the genus Amaranthus; previously characterized by $\mathrm{x}=16$ or $\mathrm{x}=17$. The karyotype of $A$. tenuifolius shows distinct features and is more symmetrical than that of other 14 grain and vegetable amaranth species studied.
\end{abstract}

Key words Basic number, Karyotype, Amaranthus tenuifolius Willd.

The genus Amaranthus is widely distributed in the tropics and subtropics and is comprised of 60-75 species (Aellen 1964, Sauer 1967) out of which 15 occur in the Indian subcontinent. Some species are grown as pot herbs while others as grain crops. Two groups represent section Blitopsis Dumort and section Amaranthotypus Dumort respectively (Aellen 1964).

Chromosome numbers of nearly 30 species have been studied which show that the genus is dibasic $(x=16,17)$ and is diploid except for a solitary tetraploid $(2 \mathrm{n}=64, \mathrm{x}=16)$ species, A. dubius Mart ex. Thell. (Pal 1971, Madhusoodanan and Nazeer 1983, Greizerstein and Poggio 1994, Greizerstein et al. 1997). The present study reports for the first time the chromosome number in $A$. tenuifolius Willd. which also gives a new basic number for the genus.

\section{Materials and methods}

A. tenuifolius, a wild delicate trailing herb with very small leaves and seeds, is distributed in the plains of North and South India (Fig. 1). The present study is based on the material collected from 'Katothital' a place $8 \mathrm{~km}$ from Lucknow. For karyotypic studies actively growing roots $(1.0-1.5 \mathrm{~cm}$ long) were excised from germinated seeds and pretreated with $0.002 \mathrm{M}$ aqueous solution of 8-hydroxyquinoline for $3 \mathrm{~h}$ at $15-17^{\circ} \mathrm{C}$. After washing these were fixed in $1: 3$ acetic alcohol for $24 \mathrm{~h}$. The root tips were washed and hydrolysed in $5 \mathrm{~N} \mathrm{HCl}$ for $30 \mathrm{~min}$ and stained with Feulgen for $2 \mathrm{~h}$ then squashed in $1 \%$ iron acetocarmine to further intensify the stain. The centromeric nomenclature of Schlarbaum and Tsuchiya (1984) was followed and degree of symmetry/asymmetry of karyotypes has been estimated following Stebbins (1958). For meiosis young flower buds were fixed in Carnoy's fluid for $24 \mathrm{~h}$ and squashed in $1 \%$ acetocarmine.

\section{Results and discussion}

Somatic chromosome number of $2 n=28$ has been observed in the present material (Fig. 2) which is a new basic number for the genus Amaranthus. Fourteen pairs of chromosomes have been arranged in decreasing order of total lengths (Figs. 2, 5) and the mean karyotype measurements from three good spreads are presented in Table 1. Based on the location of primary (centromere) constriction the karyotype formula of $A$. tenuifolius is $1 \mathrm{M}+2 \mathrm{~m}+7 \mathrm{msm}+4 \mathrm{sm}$ according to the nomenclature system of Schlarbaum and Tsuchiya (1984) and it belongs to $1 \mathrm{~b}$ class (Stebbins 1958 ) taking into account the ratio between the longest and shortest chromosome (2.17) and maxi- 
mum r-index (2.30) (Table 1). The $\mathrm{TF} \%$ is 38.95 which shows that the karyotype is moderately asymmetrical.

The diakinesis and metaphase I of meiosis also show 14II and at diakinesis one bivalent attaches to the nucleolus (Figs. 3, 4). The mean chiasma frequency per cell calculated from an analysis of 15 cells was $24.40 \pm 0.54$. Further course of meiosis was regular with 14 : 14 distribution at anaphase I resulting in normal pollen and seed fertility.

The chromosome numbers on about 30 species reported so far show that $2 \mathrm{n}=28$ in $A$. tenuifolius is a new basic number and the genus is therefore tribasic $x=14,16,17$. Detailed karyotypic studies have been done on 14 grain and vegetable species representing $\mathrm{x}=16$ or 17 (Madhusoodanan and Nazeer 1983, Greizerstein and Poggio 1994, Greizerstein et al. 1997). A comparison of the karyotypes shows that $A$. tenuifolius has the most symmetrical and primitive karyotype in the absence of any chromosome with arm ratio $>2.5$ (Table 1 ). In contrast to this the complements of other species studied have 7 to 18 chromosome pairs with arm ratio $>3.0$ and that of $A$. lividus $\mathrm{L}$. is most asymmetrical and advanced with 10 pairs of telocentric chromosomes (Madhusoodanan and Nazeer 1983, Greizerstein and Poggio 1994, Greizerstein et al. 1997). However, the

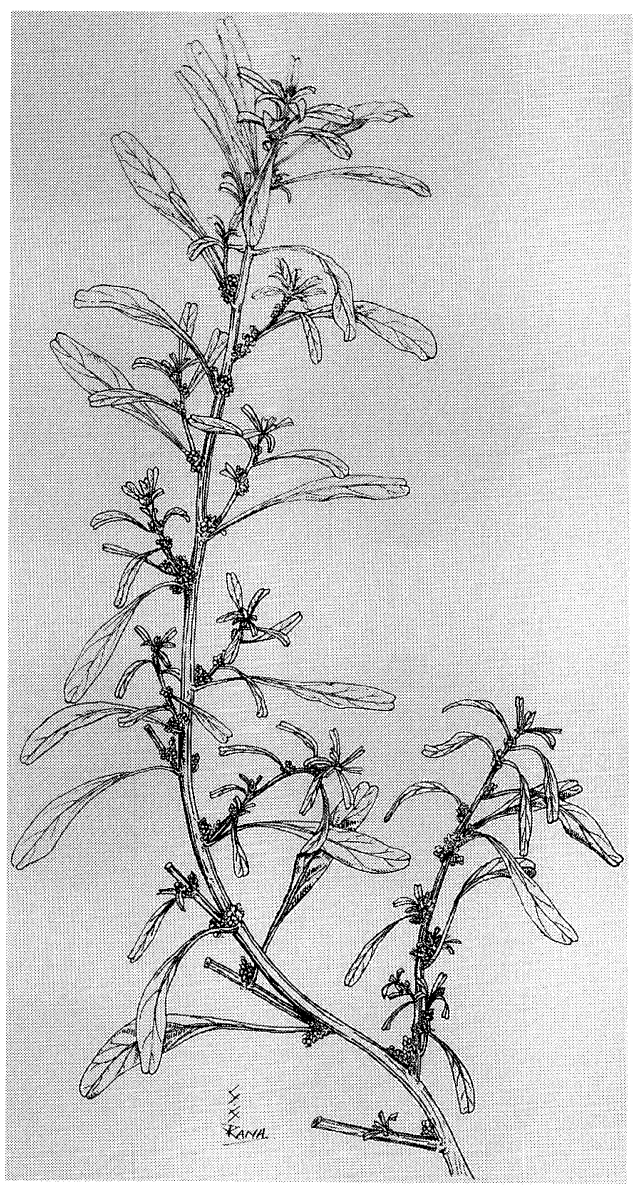

Fig. 1. A. tenuifolius $\times 0.74$.

Table 1. Chromosome measurements and classification of A.tenuifolius

\begin{tabular}{|c|c|c|c|c|c|}
\hline $\begin{array}{c}\text { Chromosome } \\
\text { pair } \\
\text { number }\end{array}$ & $\begin{array}{l}\text { Total length } \\
\qquad(\mu \mathrm{m}) \\
\text { Mean } \pm \text { S.D. }\end{array}$ & $\begin{array}{l}\text { Length of long } \\
\text { arm }(\mu \mathrm{m}) \\
\text { Mean } \pm \text { S.D. }\end{array}$ & $\begin{array}{l}\text { Length of short } \\
\text { arm }(\mu \mathrm{m}) \\
\text { Mean } \pm \text { S.D. }\end{array}$ & $\begin{array}{c}\text { r-index } \\
\text { Mean } \pm \text { S.D. }\end{array}$ & Classification \\
\hline 1 & $2.22 \pm 0.05$ & $1.31 \pm 0.02$ & $0.91 \pm 0.02$ & $1.43 \pm 0.05$ & $\mathrm{msm}$ \\
\hline 2 & $2.05 \pm 0.04$ & $1.17 \pm 0.03$ & $0.88 \pm 0.03$ & $1.32 \pm 0.05$ & $\mathrm{~m}$ \\
\hline 3 & $2.00 \pm 0.04$ & $1.20 \pm 0.02$ & $0.80 \pm 0.01$ & $1.50 \pm 0.04$ & $\mathrm{msm}$ \\
\hline 4 & $1.99 \pm 0.03$ & $1.28 \pm 0.01$ & $0.71 \pm 0.01$ & $1.80 \pm 0.03$ & $\mathrm{sm}$ \\
\hline 5 & $1.54 \pm 0.01$ & $0.97 \pm 0.01$ & $0.57 \pm 0.01$ & $1.70 \pm 0.04$ & $\mathrm{msm}$ \\
\hline 6 & $1.52 \pm 0.02$ & $1.06 \pm 0.02$ & $0.46 \pm 0.02$ & $2.30 \pm 0.02$ & $\mathrm{sm}$ \\
\hline 7 & $1.48 \pm 0.02$ & $0.74 \pm 0.03$ & $0.74 \pm 0.01$ & $1.00 \pm 0.01$ & $\mathrm{M}$ \\
\hline 8 & $1.48 \pm 0.03$ & $0.77 \pm 0.01$ & $0.71 \pm 0.02$ & $1.08 \pm 0.03$ & $\mathrm{~m}$ \\
\hline 9 & $1.48 \pm 0.01$ & $0.91 \pm 0.02$ & $0.57 \pm 0.03$ & $1.59 \pm 0.05$ & $\mathrm{msm}$ \\
\hline 10 & $1.45 \pm 0.02$ & $0.91 \pm 0.01$ & $0.54 \pm 0.01$ & $1.68 \pm 0.02$ & $\mathrm{msm}$ \\
\hline 11 & $1.40 \pm 0.03$ & $0.86 \pm 0.01$ & $0.54 \pm 0.02$ & $1.59 \pm 0.02$ & $\mathrm{msm}$ \\
\hline 12 & $1.36 \pm 0.01$ & $0.91 \pm 0.01$ & $0.45 \pm 0.01$ & $2.02 \pm 0.01$ & $\mathrm{sm}$ \\
\hline 13 & $1.31 \pm 0.03$ & $0.83 \pm 0.01$ & $0.48 \pm 0.01$ & $1.72 \pm 0.02$ & $\mathrm{msm}$ \\
\hline 14 & $1.02 \pm 0.02$ & $0.71 \pm 0.01$ & $0.31 \pm 0.01$ & $2.29 \pm 0.03$ & $\mathrm{sm}$ \\
\hline
\end{tabular}




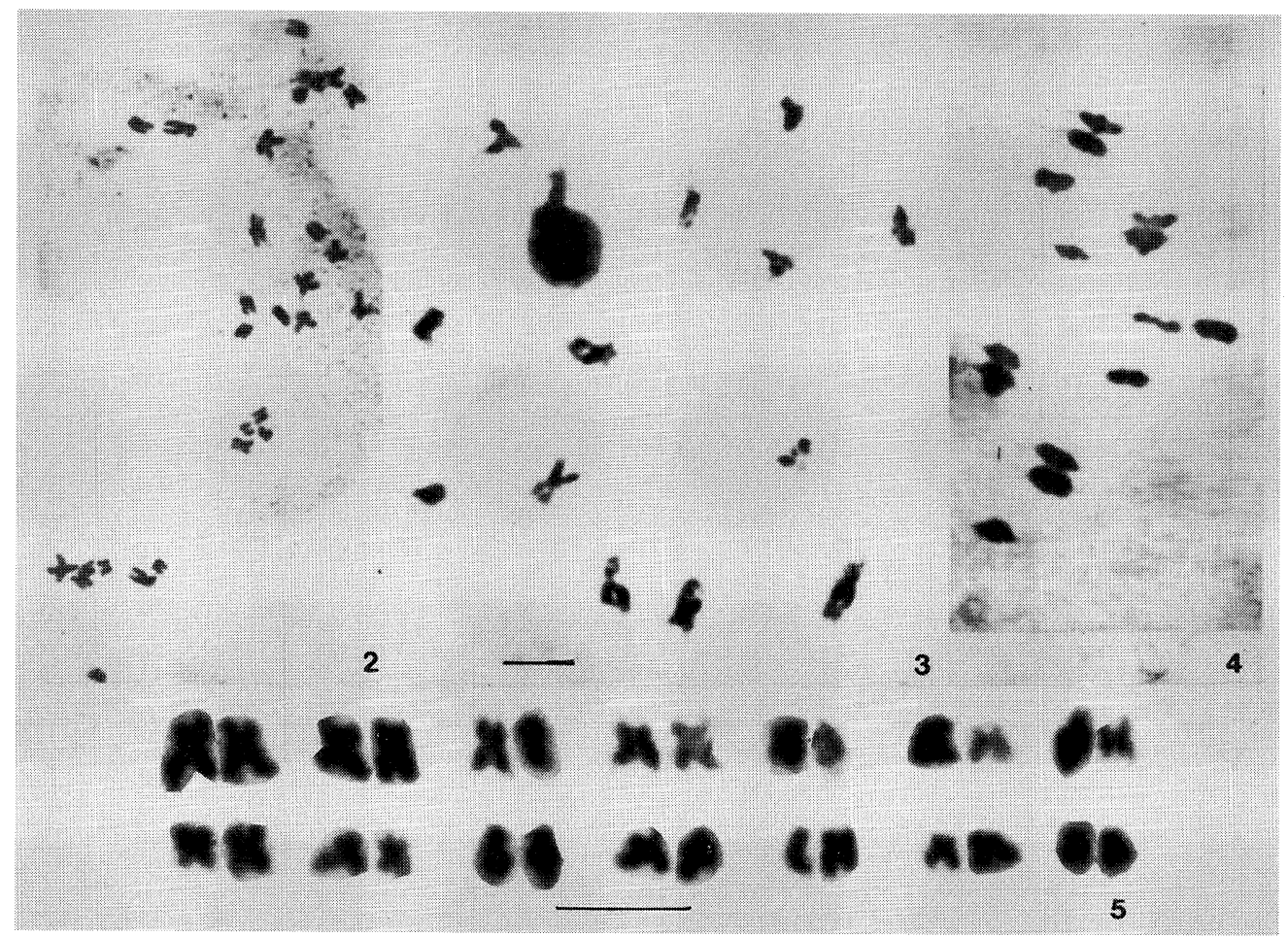

Figs. 2-5. 2) Somatic metaphase $(2 \mathrm{n}=28)$; 3) PMC at diakinesis, 14II; 4) Metaphase I, 14II, Scale $=5 \mu \mathrm{m} ; 5)$ Karyotype $(2 \mathrm{n}=28)$, Scale $=5 \mu \mathrm{m}$.

present species is very specialized morphologically in having perianths subtending the utricle and the smallest seeds so far observed among all the species studied (Pal, observation).

It is not, however, possible to derive the origin and relationships between different basic numbers on the basis of gross karyotypic studies. A study of dibasic interspecific cross between white seeded A. hypochondriacus L. $(\mathrm{n}=16)$ and black seeded wild A. hybridus L. $(\mathrm{n}=17)$ showed that the latter number originated from the former by primary trisomy (Pal et al. 1982). A similar attempt to study the cross between $A$. tenuifolius and A. lividus $(\mathrm{n}=17)$ failed as the $\mathrm{F}_{1}$ hybrids did not produce any inflorescence.

\section{Acknowledgements}

The authors are grateful to Director, National Botanical Research Institute, Lucknow for facilities.

\section{References}

Aellen, P. 1964. Amaranthaceae. In: Hegi, G. (ed.) Illustrierte Flore von Mitteleuropa, 2. Aufl., Vol. III (2), pp. 461-532, Carl Hanser, Munchen.

Greizerstein, E. J. and Poggio, L. 1994. Karyological studies in grain amaranths. Cytologia 59: 25-30.

-, Naranjo, C. A. and Poggio, L. 1997. Karyological studies in five wild species of Amaranthus. Cytologia 62: 115-120.

Madhusoodanan, K. J. and Nazeer, M. A. 1983. Comparative morphology of the somatic karyotypes of vegetable amaranths and its phylogenetic significance. Cytologia 48: 237-244.

Pal, M. 1971. Evolution and improvement of cultivated amaranths II. Polyhaploid plant of Amaranthus dubius. Indian J. Genet. 31: $397-402$. 
- Pandey, R. M. and Khoshoo, T. N. 1982. Evolution and improvement of cultivated amaranths IX. Cytogenetic relationships between the two basic chromosome numbers. J. Hered. 73: 353-356.

Sauer, J. D. 1967. The grain amaranths and their relations. A revised taxonomic and geographic survey. Ann. Missouri Bot. Gard. 54: 103-137.

Schlarbaum, S. E. and Tsuchiya, T. 1984. The chromosomes of Cunninghamia konishii, C. lanceolata and Taiwania cryptomerioides (Taxodiaceae). Pl. Syst. Evol. 145: 169-181.

Stebbins, G. L. 1958. Longevity, habitat and release of genetic variability in the higher plants. Cold Spring Herb. Symp. Plant Biol. 23: 365-378. 